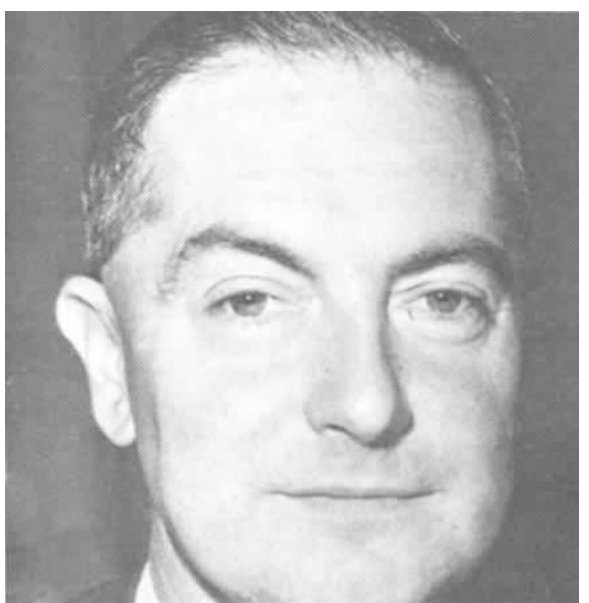

\section{Top Scottish}

\section{astronomer resigns after staffing row}

Professor Vincent Reddish (above), director of the Royal Observatory, Edinburgh (ROE), handed in his resignation last week to the UK Science Research Council (SRC) which runs the observatiory. When he relinquishes the directorship next September, he will also leave two associated posts, Astronomer Royal for Scotland and Regius Professor of Astronomy at Edinburgh University.

Professor Reddish's decision to resign has come after a prolonged dispute with the SRC over filling some senior posts, in particular that of head of technology. Administrators within the SRC would like to see the post go to an engineer. Reddish would like it to be given to an astronomer with some technological experierice, who could interchange with astronomers at the observatory's other telescopes in Hawaii and Australia. The resulting deadlock has led to some posts remaining unfilled for years, according to Professor Reddish, and the lack of some senior staff is now beginning to impair the work of the observatory.

The SRC is trying to persuade Reddish to postpone or reconsider his resignation. It would like to readvertise the head of technology post inviting both engineers and astronomers to apply. The ideal candidate, according to an SRC spokesman, would be someone who is primarily an astronomer with a great interest in or some experience of associated engineering. Reddish feels that the reforms needed to make him change his mind are primarily too great for the SRC to implement. "In principle," he says, "the problem is essentially who decides how to do the work here and the kinds of skill needed to do it." In the event of no successful settlement, he plans to retire from astronomy altogether and move into business.

\title{
Appleton and Rutherford to merge
}

Ar a meeting on 18 October, the Council of the UK Science Research Council (SRC) took the decision to close down its Appleton Laboratory at Slough and move it to the Rutherford Laboratory, also run by the SRC, at Chilton in Oxfordshire. The reasons for the merger are scientific, says the SRC. "Bringing these teams together would be the best way of doing their scientific work", according to Dr Brian Oakley, SRC Secretary.

The Appleton Laboratory is responsible for managing most of the UK's scientific space programme, which includes satellites, balloons and rockets, for scientists working in universities. The Rutherford Laboratory has always been the home-based focus of the UK effort in high energy physics at CERN. With the closure of its particle accelerator, Nimrod, earlier this year, however, it has had to diversify. It now houses a central laser facility. computing facilities and is building a central spallation neutron source.

The SRC hopes that two activities in particular, space work and radiocommunications, will benefit from the amalgamation of skills. At present work on both of these is done mainly at the Appleton Laboratory, although Rutherford has provided some engineering support for space projects in the past. Most recently, it helped design the stratospheric and mesospheric sounder for NASA's Nimbus-G satellite, launched towards the end of October. And it is currently working on the design of a millimetre wave radiotelescope with Appleton.

However some of the scientific staff at Appleton are far from content with the move. "The SRC came to a hasty decision without considering in

\section{Greater powers for Dutch science minister}

THE Dutch minister for science policy, Dr Marius Peijnenburg, has recently extended his role beyond that of coordinator. Together with one or two other ministers he now steers scientific research in government institutes and industrial laboratories. So far this has been the government's task.

With the minister for education and science, Peijnenburg will now be involved in decision-making at an early stage in university research as well as that carried out in the institutes of the Royal Netherlands Academy of Sciences. He will atso be involved in formulating policy for the energy research centre, the aviation and space laboratory and the institute for aircraft development, which until now came solely under other ministers. Peijnenburg will also control TNO, the sufficient detail all the points we would have liked them to" said Dr Jo King, Chairman of the staff side at Appleton. He feels there is little advantage to be gained from the move. Usually, he says, satellites are built in several different places and put together in one place. This would still have to happen even when the two laboratories merge. In the case of radio propagation work, Dr King claims that there will be too much radiointerference at Rutherford to make such work effective. "We are making very sensitive radio receivers" he says "and being asked to put them in one of the noisiest places in the UK"

The move is expected to take five years to complete. Appleton will be receiving data from the UK Ariel 6 satellite, to be launched next year, and the UK/NASA/Dutch satellite, IRAS, which will be launched in 1981. Final transfer to Rutherford therefore cannot be completed until those satellites cease to be operational. The bulk of the move will take place between 1980-83.

The engineering support at Appleton is weaker than that at Rutherford, according to Dr Geoffrey Manning, Rutherford's deputy-director, because it is the smaller of the two. When they are amalgamated, he says, it should be possible to provide laboratory support for all of the UK's space programme at one site. According to another SRC official, this should maximise the chances of the UK participating with the United States in the multi-mission refurbishable satellite (mrs)-a satellite proposal which has gained much support from the astrophysicists but little enthusiasm from geophysicists.

national organisation for applied research in the natural sciences. It has a staff of about 5,000 and an annual budget of $£ 55 \mathrm{~m}$.

The 1979 research budget totals around $£ 1.5$ billion, $2.05 \%$ of the gross national product. More than $£ 0.7$ billion comes from government and $£ 0.8$ billion comes from industry (mainly from Philips. Shell. Unilever, Dutch state mines and AKZO). In 1978 and 1977 the research budget was $£ 1.4$ billion and $£ 1.2$ billion respectively. For the first time, the minister for science policy is to have his own small budget for stimulating new projects in areas such as systems analysis and technology assessment. It should increase to $£ 3 \mathrm{~m}$ a year by 1981 .

In 1979 the time spent on nonnuclear research as a percentage of 